\title{
Flow modelling of particulate matter by using baffles placed in the flue tract of wood stove
}

\author{
Nikola Kantová, ${ }^{1, *}$, Alexander Čaja ${ }^{1}$, Michal Holubčík ${ }^{1}$, and Jozef Jandačka ${ }^{1}$ \\ ${ }^{1}$ University of Žilina, Department of Power Engineering, Univerzitna 1, 01026 Žilina, Slovakia
}

\begin{abstract}
It is very important to separate particulate matter before their leaving into the air because of their harmful impact on human health. It exists a lot of devices, which can separate these particles. But their implementation and operation in small heat source can be considerably difficult on finances, and often have complex maintenance. Therefore, it is important to look for solutions of reduction the producing of particulate matter with easier maintenance and also less financial difficulty. This article deals with flow modelling of particulate matter by using baffles placed in the flue tract of wood stove. Influence of baffles is observed by using CFD simulations.
\end{abstract}

\section{Introduction}

Flue gases from biomass combustion contains relatively high amount of particles smaller than $10 \mu \mathrm{m}$ (PM10). Epidemiology studies have shown a clear correlation between the particle concentration in the air and severe health effects on human being [1]. Particles less than $2.5 \mu \mathrm{m}$ (PM2.5) can penetrate deep into human lungs, deposit in the alveolus, and even may be transported to systemic apparatus or tissue leading [2].

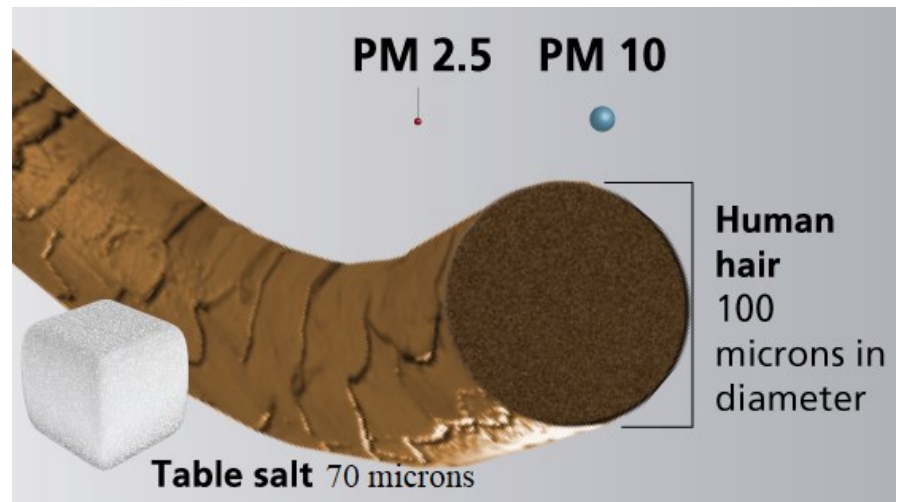

Fig. 1. Particulate matter size.

\footnotetext{
*Corresponding author: nikola.kantova@,fstroj.uniza.sk
} 
It is very important to separate particulate matter before their leaving into the air. Reduction of particulate matters can be achieved primarily by optimizing the air flow and flue gases flow in the combustion chamber, secondary by use of separator [3]. There are five major approaches for removing particulate matter based on different mechanisms. The first is settling and momentum separators by gravity, inertia and centrifugal effects such as cyclones, baffle chambers and settling chambers. The second is filtration separators by diffusion, interception, such as fabric filters, paper filters and baghouse filter. The third are wet collectors mainly scrubbers by impingement, diffusion, thermal gradients and electrostatic attraction. The fourth are acoustic separators by agglomeration resulting from sound waves and the fifth is electrostatic precipitation by electrostatic forces $[4,5]$. These implementation and operation of separators in small heat source can be considerably difficult on finances, and often have complex maintenance. There are looking for solutions of reduction the producing of particulate matter with easier maintenance and also less financial difficulty [6].

For separation of particulate matter in wood stove is designed a model of flue tract with baffles. Their effect is observed by using CFD simulations. CFD is an abbreviation for computational fluid dynamics, which is a branch of fluid mechanics that uses numerical analysis and algorithms to solve and analyse problems that involve fluid flows [7,9].

\section{Mathematical simulation}

Analysis was carried out in Ansys program by using baffles for separation. There were used three baffles placed in the flue tract of wood stove. Optimized flue tract was realized on 3D model with network of 194787 elements, which is shown in the Figure 2. All elements had aspect ratio lower than 10. Flue tract was thought as a cube with length of edge $400 \mathrm{~mm}$. The chimney had diameter of $160 \mathrm{~mm}$. Baffle was placed perpendicular to the flue track with length of $350 \mathrm{~mm}$. Particles entered into a model through a hole with dimensions 135 x 400 $\mathrm{mm}$.

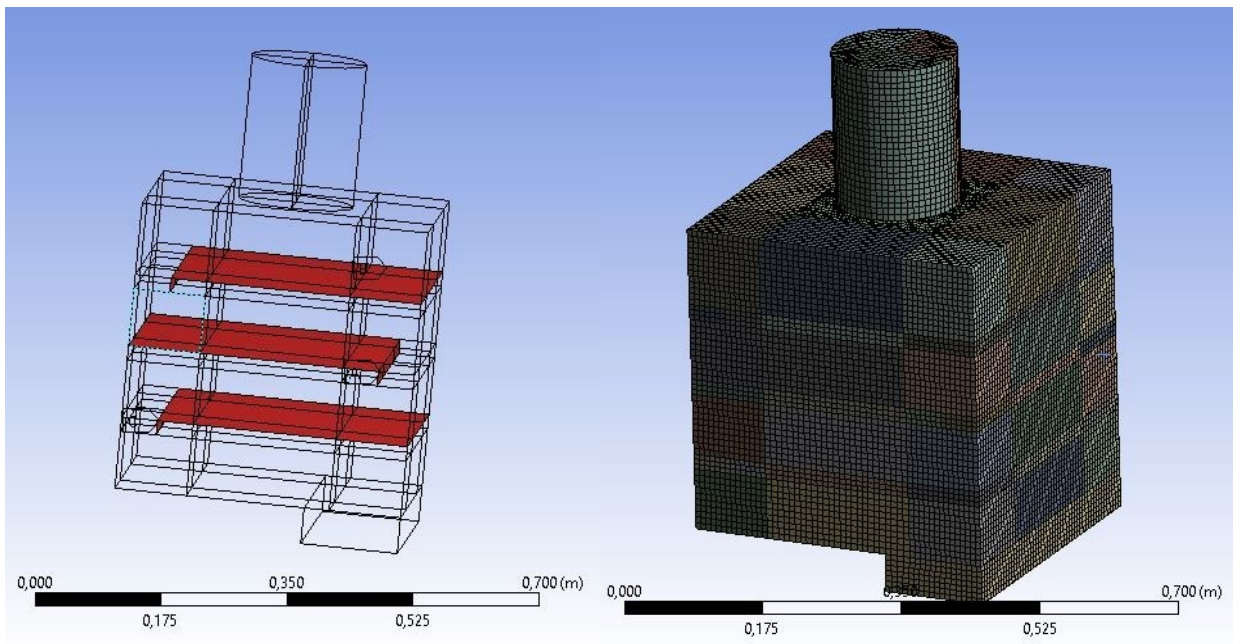

Fig. 2. 3D and mathematical model of flue tract with baffles.

The object was simulated by the k- $\varepsilon$ model with standard wall function. The flowing of particles was realized using by the trajectory of a discrete phase particle by integrating the force balance on the particle, which is written in a Lagrangian reference frame [8].

It was important to realize size distribution of particles and then use Rosin-Rammler distribution function because of determine mean parameter and spread parameter in Ansys 
program. Size distribution, which you can see in the Figure 3, was experimental determined by using of vibratory sieve shaker machine. Used sieves had the size of mesh $500 \mu \mathrm{m}, 250$ $\mu \mathrm{m}, 150 \mu \mathrm{m}, 100 \mu \mathrm{m}, 50 \mu \mathrm{m}$ and $20 \mu \mathrm{m}$. Sample of particulate matter was obtained from electrostatic precipitator after combustion of wood chips from spruce wood in the boiler with moving grate.

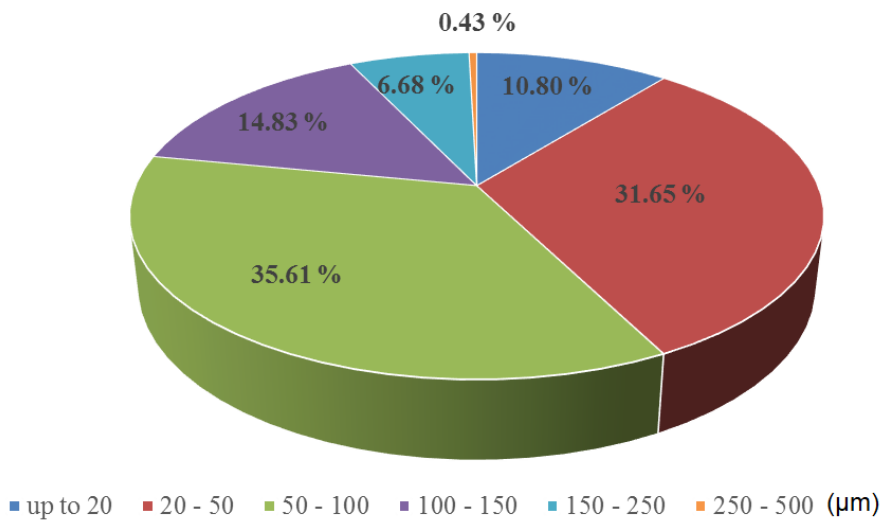

Fig. 3. Size distribution.

Particles were considered spherical and also the influence of turbulence on particle motion. Flowing was time steady, without combustion and the influence of gravity was considered. Used materials were air with a density of $0.6 \mathrm{~kg} . \mathrm{m}^{-3}$ and particles with a density of $600 \mathrm{~kg} \cdot \mathrm{m}^{-3}$. Based on the stoichiometric calculations was mass flow set on $0.0168 \mathrm{~kg} . \mathrm{s}^{-1}$.

\section{Results}

In Ansys program were created velocity profile and particle diameter profile, which you can see in the Figure 4.

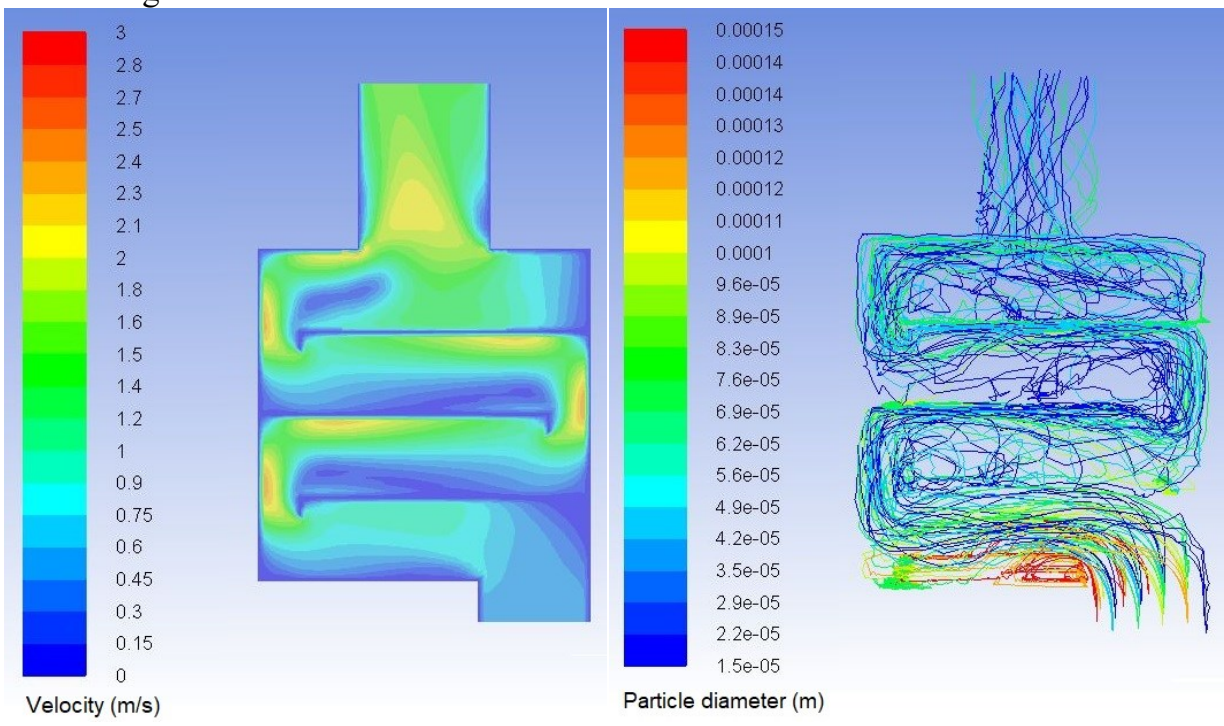

Fig. 4. Velocity and particle diameter profile. 
It is important to do not realize difficult shape of baffles, where could be big narrowing. It would cause large pressure loss and increasing in flow velocity. Maximum flow velocity was $2.5 \mathrm{~m} . \mathrm{s}^{-1}$ in this flue tract. Particles achieved bigger velocities in a places of boundary walls after a transition of the baffle and also on the bottom parts of baffles. The largest particles did not pass through first baffle. Based on the number of particles, $44.83 \%$ particles escaped and $55.17 \%$ particles captured. Based on the mass flow, $81.6 \%$ escaped and $18.4 \%$ particles captured. It is caused that the smallest particles escaped in the flue gas stream and larger particles were captured.

\section{Conclusion}

Decrease of particulate matter is necessary topic for air protection. Elimination of particulate matter can be achieved by various ways. But many separators are difficult on finances, and often have complex maintenance. Therefore, it is important to look for more useful solutions. This paper deals with flow modelling of particulate matter by using baffles placed in the flue tract of wood stove. Their effect was observed and analysed by using CFD simulations. Used baffles were effective for larger particles, which were captured. Bigger amount of smaller particles escaped in the flue gas stream.

This work has been supported by the project KEGA 033ŽU-4/2018 "Heat sources and pollution of the environment".

\section{References}

1. K.G. Nigusie, Master's thesis, online

2. Who, Health effects of particulate matter, Policy implications for countries in eastern Europe, Caucasus and central Asia, online, (2013)

3. P. Durčanský, M. Holubčík, M. Malcho, Meeting of Departments of Fluid Mechanics and Thermomechanics (2006)

4. L. Guan, G. Harvel, S. Park, J.S. Chang, 11th International Conference on Electrostatic Precipitation (2008)

5. J. Moravec, Technical Gazette, 24, 143-147

6. K. Sulovcová, J. Jandačka, R. Nosek, Power control and optimization, (2013)

7. A. Ryfa, R. Buczynski, M. Chabinski, A. Szlek, R.A. Bialecki, Thermal Engineering $\mathbf{7 3}$ (2014)

8. Fluent user' guide, online

9. S. Gavlas, P. Ďurčanský, R. Lenhard, J. Jandačka, EPJ Web of Conferences 92, (2015)

10. P. Nemec, M. Smitka, M. Malcho, Scientific world journal, 2014 (2014)

11. P. Nemec, M. Malcho, J. Jandačka, AIP Conference Proceedings, 1558, (2013) 